\title{
Ratcheting Behavior of SA508-3 Steel at Elevated Temperature: Experimental Observation and Simulation
}

\author{
Jun Tian ${ }^{1} \cdot$ Yu Yang ${ }^{1} \cdot$ Li-Ping Zhang ${ }^{1} \cdot$ Xue-Jiao Shao ${ }^{1} \cdot$ Juan Du $^{1} \cdot$ Qian-Hua Kan ${ }^{2}$
}

Received: 4 January 2017/Revised: 17 February 2017/Published online: 5 May 2017

(C) The Chinese Society for Metals and Springer-Verlag Berlin Heidelberg 2017

\begin{abstract}
A series of monotonic uniaxial tensile tests, strain-controlled and stress-controlled cyclic tests of SA508-3 steel were conducted from 25 to $350{ }^{\circ} \mathrm{C}$. Results showed that the steel exhibited temperature-dependent cyclic softening characteristic and obvious ratcheting behavior, and dynamic strain aging was observed in the range of $250-350{ }^{\circ} \mathrm{C}$. Based on experimental observations, a temperature-dependent cyclic plastic constitutive model was proposed by introducing the nonlinear cyclic softening and kinematic hardening rules, and the dynamic strain aging was also considered into the constitutive model. Comparisons between experiments and simulations were carried out to validate the proposed model at elevated temperature.
\end{abstract}

KEY WORDS: Ratcheting; Constitutive model; Dynamic strain aging; Cyclic loading; Elevated temperature

\section{Introduction}

Ratcheting, a phenomenon cannot be ignored in the safety assessment and life estimation of engineering materials and structures, is a progressive accumulation of plastic strain subjected to cyclic stressing with nonzero mean stress. For components used in nuclear engineering, both ASME and RCC-M codes have specified that the effect of ratcheting behavior on the nuclear reactor structures must be evaluated in design. However, to accurately predict the ratcheting deformation is very difficult since it is a secondary

Available online at http://link.springer.com/journal/40195

Qian-Hua Kan

qianhuakan@foxmail.com

1 Science and Technology on Reactor System Design Technology Laboratory, Nuclear Power Institute of China, Chengdu 610213, China

2 Applied Mechanics and Structure Safety Key Laboratory of Sichuan Province, School of Mechanics and Engineering, Southwest Jiaotong University, Chengdu 610031, China deformation superposed on the primary cyclic stress-strain response.

In the last three decades, numerous experiments have been performed to reveal the evolution features of ratcheting deformation of metal materials, as reviewed by Kang [1], Sai [2] and Chen et al. [3]. Experimental observations [4-8] showed that different materials demonstrated different cyclic characteristics and ratcheting behaviors, and the ratcheting behavior strongly depends on ambient temperature. Many constitutive models based on combined nonlinear isotropic and kinematic hardening rules were proposed to predict ratcheting behavior. The nonlinear kinematic hardening rule established by Armstrong and Frederick [9] is one of the important models that can reproduce the ratcheting behavior, even though it produces an over-estimation to ratcheting deformation. So far many efforts have been made to improve the accuracy of Armstrong and Frederick rule by researchers, such as Chaboche [10], Ohno and Wang [11], Abdel-Karim and Ohno [12] and Kang and Kan [13]. To describe the ratcheting behavior of the studied material reasonably, some specific modifications in the existing constitutive model have also been discussed recently. For example, Lin et al. [14] 
modified the material parameter $m_{\mathrm{i}}$ of the Ohno-Wang II kinematic hardening rule as a function of the maximum equivalent stress to predict the ratcheting deformation of AZ31B magnesium alloy.

SA508-3 steel is one of the alloyed ferritic steels, mainly equipped in the reactor pressure vessel of the first loop of the pressurized water reactor and often experiences a varied thermal loading from 25 to $350{ }^{\circ} \mathrm{C}$. Dong et al. [15] investigated the hot deformation behavior of SA508-3 steel by isothermal hot compression tests and strain rate of $0.001-0.1 \mathrm{~s}^{-1}$ and developed a physically-based constitutive model to predict the flow stress of SA508-3 steel. Sun et al. [16] also established constitutive equation to describe the mechanical response and microstructural evolution of SA508-3 steel under various hot deformation conditions. Considering temperature effects, Liu et al. [17] evaluated the fracture toughness of SA508-3 steel from 25 to $320{ }^{\circ} \mathrm{C}$ using the $J$-integral method, and observed dynamic strain aging (DSA) when the temperature exceeded $260{ }^{\circ} \mathrm{C}$ with a certain strain rate. However, there are a few open literatures about the ratcheting deformation of SA508-3 steel at present, especially at elevated temperature. Researches by Yaguchi [18] have reported that ferritic-alloyed steels generally exhibit notable viscosity and cyclic softening behavior at high temperature, which is completely different from the behaviors of austenitic stainless steels and carbon steels. Considering the importance of SA508-3 steel in nuclear plants, it is necessary to perform detailed investigation on ratcheting deformation.

Therefore, a series of monotonic tensile tests, straincontrolled and stress-controlled cyclic tests of SA508-3 steel were conducted from 25 to $350{ }^{\circ} \mathrm{C}$, respectively. Based on experimental observations, a temperature-dependent cyclic plastic constitutive model was proposed by introducing the nonlinear cyclic softening and kinematic hardening rules. Finally, experiments and simulations were carried out to validate the proposed model at elevated temperature.

\section{Experimental}

\subsection{Material and Procedure}

The material used in this work is SA508-3 steel, provided by China First Heavy Industry (CFHI). This steel was fabricated by melting, casting, forging and heat treatment (homogenization, tempering, austenitization, quenching and tempering), in sequence [17]. The initial grain size is about $20 \mu \mathrm{m}$. Its chemical composition is: C, $0.19 \%$; $\mathrm{Si}$, $0.19 \%$; Mn, $1.48 \%$; Ni, 0.78\%; Cr, 0.13\%; Mo, 0.50\%; $\mathrm{P},<0.005 \% ; \mathrm{S},<0.002 \% ; \mathrm{Cu},<0.02 \% ; \mathrm{V},<0.002 \%$; and Fe, balance. Hot-rolled bar of the SA508-3 steel was machined into round solid bar specimens for uniaxial cyclic tests. Each solid bar has a test section diameter of $10 \mathrm{~mm}$ and a gauge length of $30 \mathrm{~mm}$.

The uniaxial tensile and cyclic tests were carried out on CRIMS-RPL100 creep fatigue testing machine, equipped with a cylindrical heating oven with the highest working temperature of $900{ }^{\circ} \mathrm{C}$. Before mechanical loading at elevated temperature, the specimen would be heated in the closed oven firstly, the heating speed is about $600{ }^{\circ} \mathrm{C} / \mathrm{h}$, the final expected temperature would be held for $30 \mathrm{~min}$ to ensure a uniform temperature distribution. The uniaxial strain was measured by an extensometer in the range of 20-900 ${ }^{\circ} \mathrm{C}$. Except for the specially denoted cases, the strain rate for strain-controlled tests was set as $0.002 \mathrm{~s}^{-1}$, and the stress rate for stress-controlled cycling was fixed as $100 \mathrm{MPa} / \mathrm{s}$. The axial ratcheting strain, stress amplitude and mean stress are defined as $\left(\varepsilon_{\max }+\varepsilon_{\min }\right) / 2,\left(\sigma_{\max }-\right.$ $\left.\sigma_{\min }\right) / 2$ and $\left(\sigma_{\max }+\sigma_{\min }\right) / 2$, respectively. Here, $\varepsilon_{\max }$ and $\varepsilon_{\text {min }}$ are the maximal and minimal axial strain in each cycle, respectively; $\sigma_{\max }$ and $\sigma_{\min }$ are the maximal and minimal axial stress in each cycle, respectively.

\subsection{Monotonic Tensile Tests}

Monotonic uniaxial tensile tests were performed to realize the basic mechanical properties at different temperatures. Figure 1a shows the monotonic tensile stress-strain curves from 25 to $350{ }^{\circ} \mathrm{C}$ with strain rate of $0.002 \mathrm{~s}^{-1}$. It can be found that the stress decreases with increasing temperature from 25 to $200{ }^{\circ} \mathrm{C}$, but increases in the range of 250 to $350{ }^{\circ} \mathrm{C}$. This is the reason that dynamic strain aging occurs in the range of 250 to $350{ }^{\circ} \mathrm{C}$, which can intensely promote the interactions of dislocation and point defect, resulting in a remarkable enhancement of deformation resistance. $\mathrm{Xu}$ et al. [19] also have performed uniaxial tension tests on SA508-3 steel and found that the dynamic strain aging region was in the same temperature range of $250-350{ }^{\circ} \mathrm{C}$ at a strain rate of $1.2 \times 10^{-3} \mathrm{~s}^{-1}$. Similar phenomenon can also be observed in SS304 stainless steel from 400 to $600{ }^{\circ} \mathrm{C}[8]$.

\subsection{Strain Cyclic Tests}

To observe the cyclic characteristics of SA508-3 steel, the symmetrical strain-controlled cycling with strain amplitude of $0.6 \%$ at different temperatures was carried out, as shown in Fig. 2.

It can be seen from Fig. 2 that SA508-3 steel exhibits remarkably cyclic softening characteristic at $25^{\circ} \mathrm{C}$. That is, a decreased stress amplitude can be observed with increasing number of cycles. At $350{ }^{\circ} \mathrm{C}$, the steel initially shows a cyclic softening characteristic, but after 60 cycles, it changes into cyclic stable character, i.e., hysteresis loops 
(a)

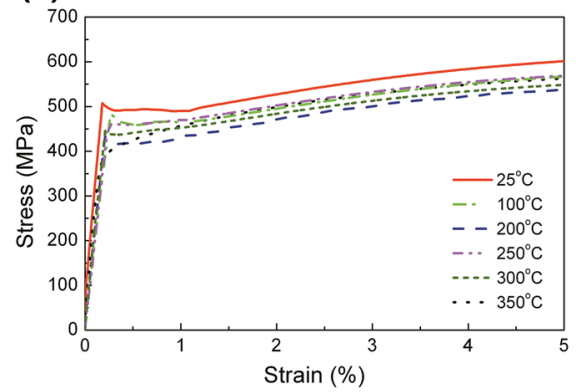

(b)

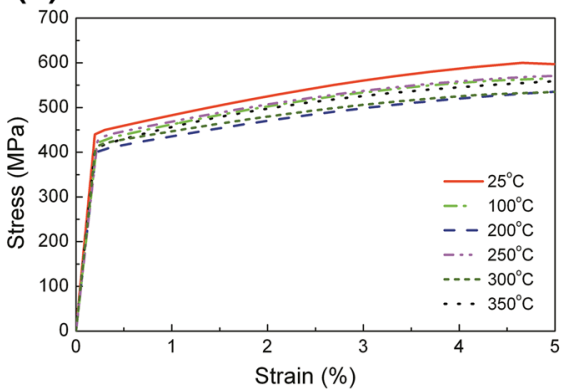

(c)

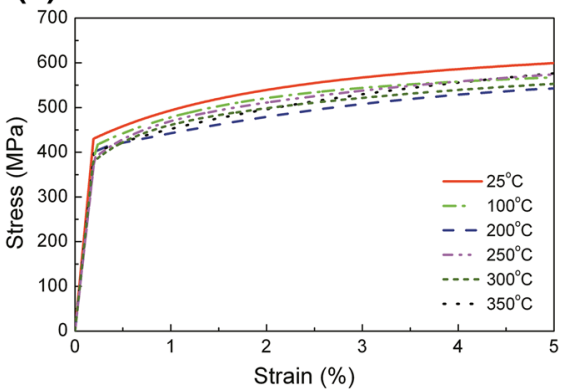

Fig. 1 Monotonic tensile stress-strain curves at different temperatures: a experiments, $\mathbf{b}$ simulations by the proposed model, $\mathbf{c}$ simulations by the Chaboche model

(a)

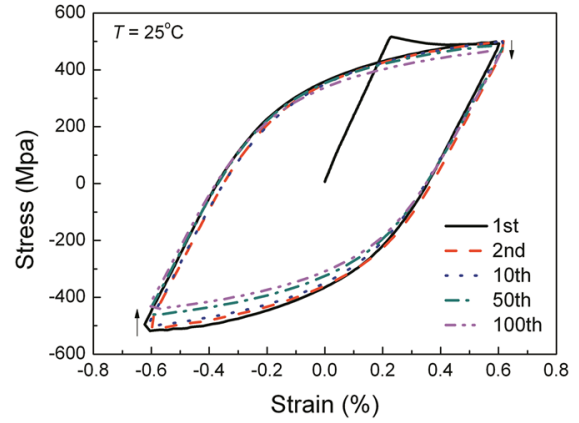

(b)

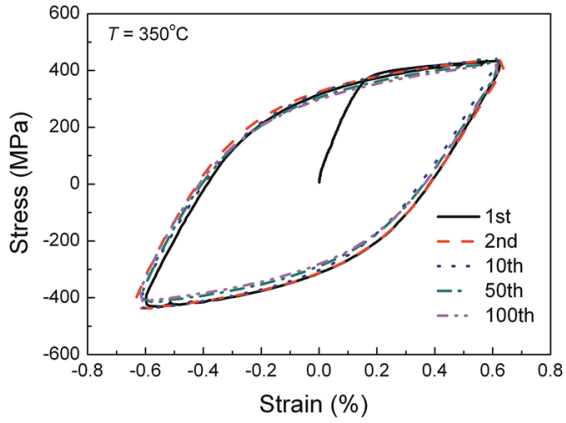

(c)

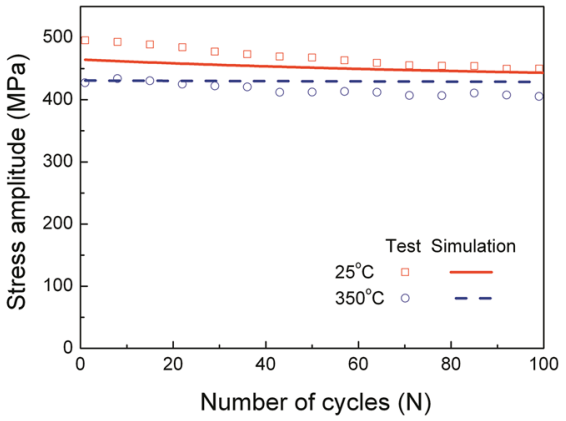

Fig. 2 Experimental stress-strain curves of SA508-3 for uniaxial strain cycling under strain amplitude of $0.6 \%$ at a $25{ }^{\circ} \mathrm{C}$; b $350{ }^{\circ} \mathrm{C}$; c experimental and simulated stress amplitudes versus number of cycles by the proposed model

keep almost unchanged. It implies that SA508-3 steel exhibits a temperature-dependent cyclic deformation behavior, which must be addressed in constitutive model.

\subsection{Stress Cyclic Tests}

To investigate the influences of mean stress, stress amplitude, loading history and temperature on the ratcheting, two-step stress-controlled cyclic tests were performed at six temperatures with various mean stresses and stress amplitudes. The loading cases are listed in Table 1. The expression " $50 \pm 450$ " here demonstrates that the mean stress is $50 \mathrm{MPa}$ and the stress amplitude is $450 \mathrm{MPa}$. There are two loading cases at each temperature, with the same mean stress or stress amplitude, respectively. For each step, total of 50 cycles were proscribed unless the specimen goes broken in advance.

The experimental results are shown in Fig. 3. It is found that the ratcheting strain rate increases with increasing mean stress or stress amplitude. In the range of $25-250{ }^{\circ} \mathrm{C}$, SA508-3 steel exhibits cyclic softening characteristic, and the ability of deformation resistance is obviously strengthened from 300 to $350{ }^{\circ} \mathrm{C}$, which implies that SA508-3 steel exhibits obvious temperature-dependent ratcheting behaviors.
Table 1 Loading cases of stress cyclic tests at different temperatures for SA508-3 steel

\begin{tabular}{llll}
\hline Case & Temperature $\left({ }^{\circ} \mathrm{C}\right)$ & First step $(\mathrm{MPa})$ & Second step $(\mathrm{MPa})$ \\
\hline 1 & 25 & $50 \pm 450$ & $50 \pm 475$ \\
2 & 25 & $50 \pm 450$ & $75 \pm 450$ \\
3 & 100 & $50 \pm 450$ & $50 \pm 475$ \\
4 & 100 & $50 \pm 450$ & $75 \pm 450$ \\
5 & 200 & $50 \pm 425$ & $50 \pm 450$ \\
6 & 200 & $50 \pm 425$ & $75 \pm 425$ \\
7 & 250 & $50 \pm 425$ & $50 \pm 450$ \\
8 & 250 & $50 \pm 425$ & $75 \pm 425$ \\
9 & 300 & $50 \pm 425$ & $50 \pm 450$ \\
10 & 300 & $50 \pm 425$ & $75 \pm 425$ \\
11 & 350 & $50 \pm 425$ & $50 \pm 450$ \\
12 & 350 & $50 \pm 425$ & $75 \pm 425$ \\
\hline
\end{tabular}

To indicate the ratcheting behaviors at different temperatures, a stress-controlled cycling with the mean stress of $50 \mathrm{MPa}$ and stress amplitude of $450 \mathrm{MPa}$, at the temperature range of $25-350{ }^{\circ} \mathrm{C}$, with 30 loading cycles for each temperature history, has been conducted. Experiments with different temperature histories are compared with those of constant temperatures, as shown in Fig. 4. 
(a)

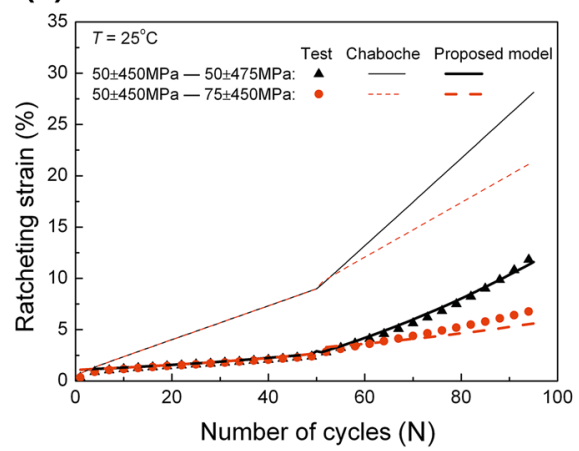

(d)

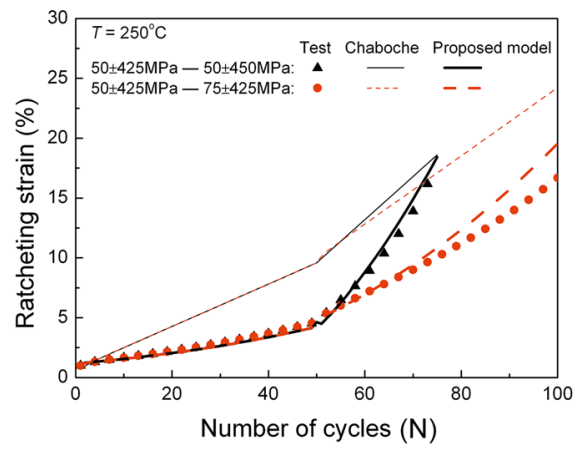

(b)

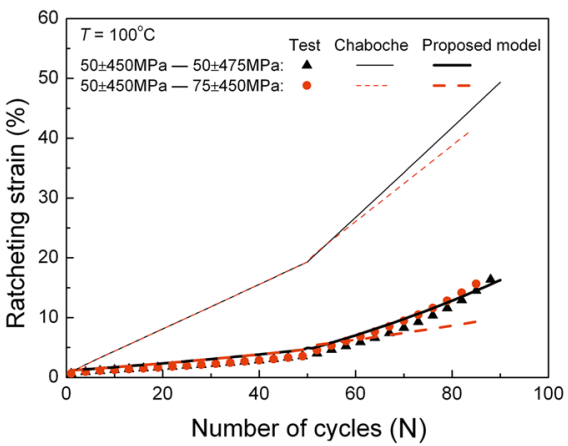

(e)

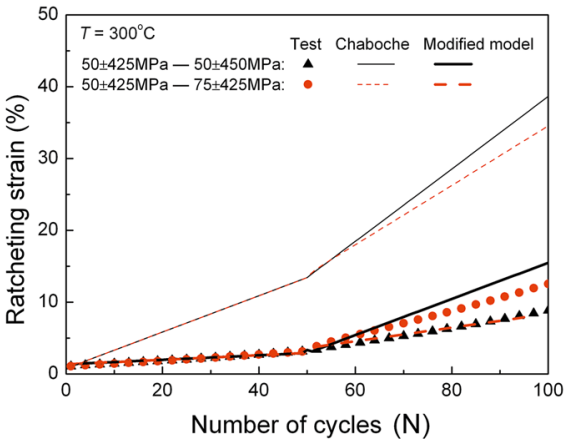

(c)

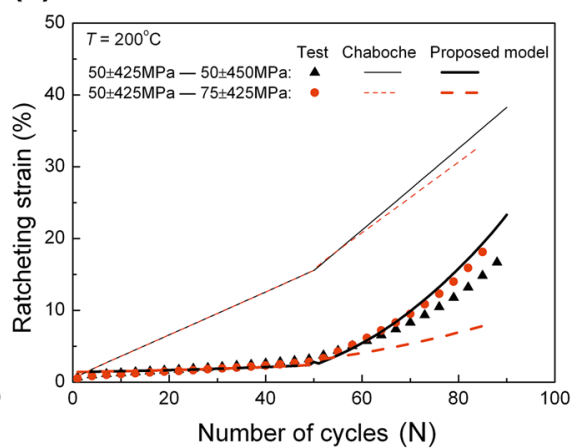

(f)

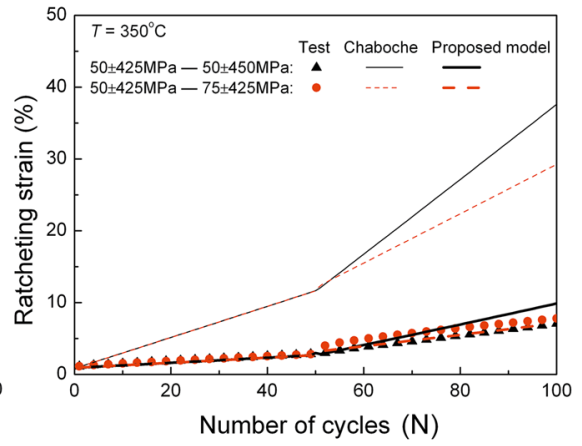

Fig. 3 Experimental and simulated curves of ratcheting strain versus number of cycles at a $25{ }^{\circ} \mathrm{C}$; b $100{ }^{\circ} \mathrm{C}$; c $200{ }^{\circ} \mathrm{C}$; d $250{ }^{\circ} \mathrm{C}$; e $300{ }^{\circ} \mathrm{C}$; f $350{ }^{\circ} \mathrm{C}$

It can be seen from Fig. 4 that at $25{ }^{\circ} \mathrm{C}$, SA508-3 steel exhibits cyclic softening characteristic, and the evolution of ratcheting can be divided into three stages regarding to the ratcheting strain rate. Specifically, the first eight cycles can be defined as stage I, with decreasing ratcheting strain rate, while the stage II is up to the 40th cycle, with a nearly constant rate, and the remained stage III exhibits a rapidly increasing rate. The tertiary evolution of ratcheting can also be observed at $200{ }^{\circ} \mathrm{C}$, but the rate increases more sharply, resulting in a more quickly failure of the specimen due to large deformation. However, because of dynamic strain aging effect, the steel shows cyclic stable character at $350{ }^{\circ} \mathrm{C}$, with a nearly constant ratcheting strain rate. At the same cycles, the ratcheting strain at $350{ }^{\circ} \mathrm{C}$ is higher than that at $25^{\circ} \mathrm{C}$, but is lower than that at $250{ }^{\circ} \mathrm{C}$. For the test considering temperature history in Fig. 4, the ratcheting strain is lower than that at the isothermal test of $200{ }^{\circ} \mathrm{C}$. But after the temperature turns to $350{ }^{\circ} \mathrm{C}$, the ratcheting strain is apparently greater than that at the isothermal test of $350{ }^{\circ} \mathrm{C}$, which implies
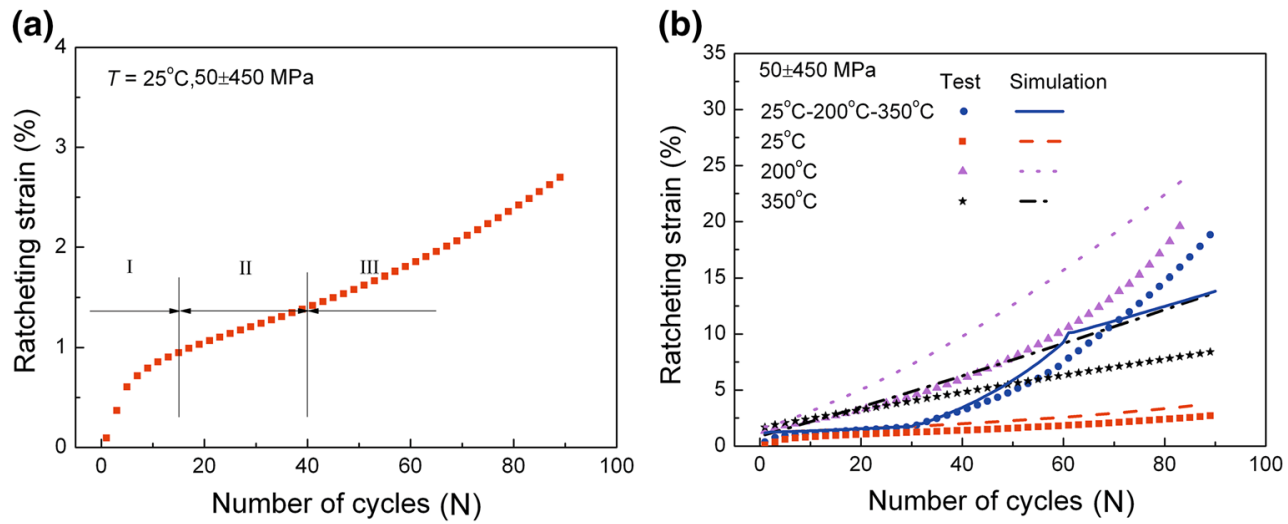

Fig. 4 Experimental and simulated curves of ratcheting strain versus number of cycles by the proposed model $\mathbf{a}$ at $25{ }^{\circ} \mathrm{C}$; $\mathbf{b}$ at different temperatures 
that the temperature history obviously influences the ratcheting deformation.

\section{Simulations and Discussion}

\subsection{A Temperature-Dependent Cyclic Plasticity Model}

Based on the initial isotropic elasticity and associated plastic flow rules at small deformation, and introducing the temperature term, the main constitutive equations of cyclic plasticity are expressed as follows:

$\dot{\boldsymbol{\varepsilon}}=\dot{\boldsymbol{\varepsilon}}^{\mathrm{e}}+\dot{\boldsymbol{\varepsilon}}^{\mathrm{p}}+\dot{\boldsymbol{\varepsilon}}^{\mathrm{T}}$,

$\dot{\boldsymbol{\varepsilon}}^{e}=\boldsymbol{D}(T)^{-1}: \dot{\sigma}$,

$\dot{\boldsymbol{\varepsilon}}^{\mathrm{p}}=\sqrt{1.5} \dot{p} \frac{\boldsymbol{s}-\boldsymbol{\alpha}}{\|\boldsymbol{s}-\boldsymbol{\alpha}\|}$,

$\dot{\boldsymbol{\varepsilon}}^{T}=\alpha \dot{T}$,

$F_{y}=\sqrt{1.5(s-\boldsymbol{\alpha}):(s-\boldsymbol{\alpha})}-Q$,

where $\dot{\boldsymbol{\varepsilon}}, \dot{\boldsymbol{\varepsilon}}^{\mathrm{e}}, \dot{\boldsymbol{\varepsilon}}^{\mathrm{p}}$ and $\dot{\boldsymbol{\varepsilon}}^{\mathrm{T}}$ are the rate of total strain, elastic strain, plastic strain and thermal strain tensors, respectively; $\boldsymbol{D}$ is the fourth-ordered elasticity tensor; $\dot{p}$ is the rate of accumulated plastic strain; $\alpha$ is the thermal expansion coefficient and $\dot{T}$ is the rate of temperature; $\boldsymbol{s}, \boldsymbol{\alpha}$ and $Q$ represent deviatoric stress tensor, back stress tensor and isotropic deformation resistance, respectively; II II denotes the norm.

The nonlinear kinematic hardening rule can be employed to develop the constitutive model of ratcheting. Chaboche [20] decomposed the back stress in the nonlinear hardening rule proposed by Armstrong and Frederick [9] into $M$ independent components as:

$\boldsymbol{\alpha}=\sum_{i=1}^{M} \boldsymbol{\alpha}_{i}$

$\dot{\boldsymbol{\alpha}}_{i}=\frac{2}{3} C_{i} \dot{\boldsymbol{\varepsilon}}^{\mathrm{p}}-r_{i} \boldsymbol{\alpha}_{i} \dot{p}$

where $\boldsymbol{\alpha}_{i}$ is component of back stress $\boldsymbol{\alpha} ; C_{i}$ and $r_{i}$ are material constants. The Chaboche rule had been implemented into finite element codes, such as ANSYS and ABAQUS, but it gives an overestimated prediction in ratcheting deformation. The constants $C_{i}$ represent plastic hardening moduli and can be calculated from monotonic tensile stress versus accumulated plastic strain curves at different temperatures according to the fixed $r_{i}$, as shown in Fig. 5. It is found that the plastic hardening moduli $C_{i}$ depends on accumulated plastic strain and temperature and can be described by the following expression:

$C(p, T)=\exp \left(a(T)+b(T) p+c(T) p^{2}\right)$,

where $a, b$ and $c$ are material constants and can be determined from experimental results shown in Fig. 5. As an example, the exponential relationships between the plastic hardening moduli $C$ and accumulated plastic strain at 200 and $300{ }^{\circ} \mathrm{C}$ were obtained by differentiating the curves of stress versus accumulated plastic strain.

Therefore, the nonlinear kinematic hardening rule can be expressed as:

$\dot{\alpha}(T)=\frac{2}{3} C(p, T) \dot{\varepsilon}^{\mathrm{p}}-r(T) \boldsymbol{\alpha}(T) \dot{p}$,

where plastic modulus $C$ becomes the function of effective plastic strain $p$ and temperature $T$, and $r$ is only relevant to $T$.

As shown in Fig. 2c, the responded stress amplitude decreases exponentially with increasing number of cycles, and thus the new evolution equation for the isotropic deformation resistance $Q$ is adopted,

$\dot{Q}(p, T)=\gamma(T)\left(Q_{\mathrm{sa}}(T)-Q(p, T)\right) \dot{p}+\frac{\partial Q(p, T)}{\partial T} \dot{T}$,

where $Q_{\mathrm{sa}}(T)$ is the saturated isotropic deformation resistance related to temperature, and $\gamma(T)$ is a coefficient to control the evolution rate of $Q(p, T)$. When the accumulated plastic strain is zero, Eq. (10) has an initial value $Q_{0}$, i.e., initial deformation resistance. It should be noted that the yield stress in monotonic tension is significantly different from the subsequent cyclic one for cyclic softening or hardening materials [21]. To improve the proposed model's accuracy, the initial value of isotropic deformation resistance $Q_{0}$ was changed into $Q_{1}$ after finishing tension in the first cycle.

\subsection{Temperature-Dependent Material Parameters}

In order to predict the temperature-dependent cyclic deformation behavior, the relationship between parameters and temperature must be calibrated firstly. Considering the influences of dynamic strain aging and temperature, the piecewise temperature-dependent elastic modulus can be fitting from elastic zone of tensile stress-strain curve:

$E=\left\{\begin{array}{l}\left(190.8+105.6 e^{-0.048 T}\right) \times 10^{3}, \quad 25^{\circ} \mathrm{C} \leq T \leq 250^{\circ} \mathrm{C} \\ 3900+924 T-1.28 T^{2}, \quad 250^{\circ} \mathrm{C} \leq T \leq 350^{\circ} \mathrm{C},\end{array}\right.$

The material constants for temperature-dependent kinematic hardening were fitted from tensile stress-strain curves, 
(a)

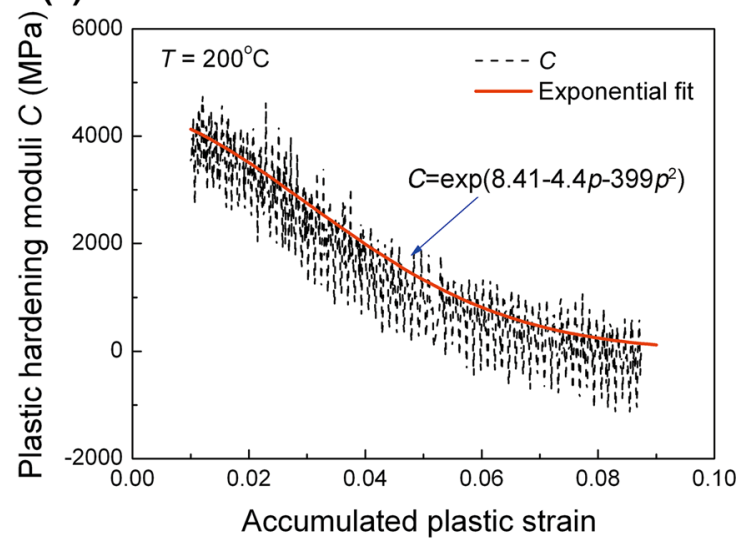

(b)

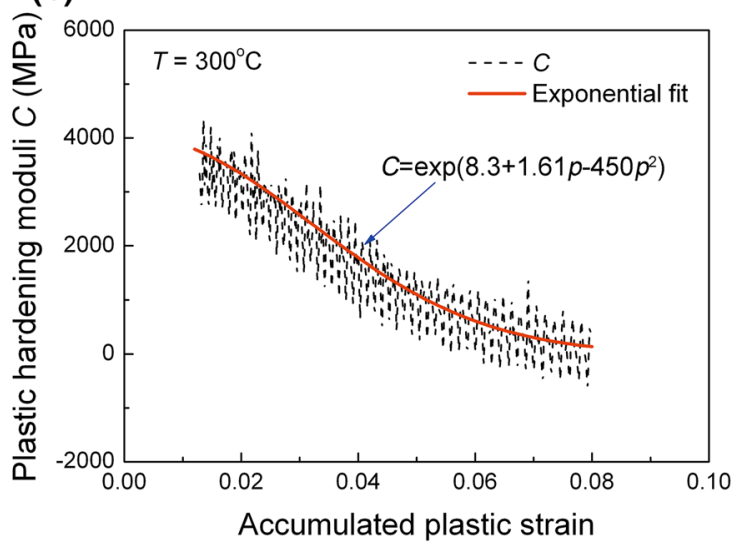

Fig. 5 Exponential relationship between the plastic hardening moduli $C$ and accumulated plastic strain at a $200{ }^{\circ} \mathrm{C} ; \mathbf{b} 300{ }^{\circ} \mathrm{C}$

$a=\left\{\begin{array}{l}8.504+7.857 \times 10^{-4} T-6.286 \times 10^{-6} T^{2}, \quad 25^{\circ} \mathrm{C} \leq T<200^{\circ} \mathrm{C} \\ 8.37+2 \times 10^{-4} T, \quad 200^{\circ} \mathrm{C} \leq T<250^{\circ} \mathrm{C} \\ 16.82-0.0596 T+1.04 \times 10^{-4} T^{2}, \quad 250^{\circ} \mathrm{C} \leq T<350^{\circ} \mathrm{C},\end{array}\right.$

$b=\left\{\begin{array}{l}0.15952-0.05 T+1.355 \times 10^{-4} T^{2}, \quad 25^{\circ} \mathrm{C} \leq T<250^{\circ} \mathrm{C} \\ -167.48+1.1084 T-0.00182 T^{2}, \quad 250^{\circ} \mathrm{C} \leq T \leq 350^{\circ} \mathrm{C},\end{array}\right.$

$c=\left\{\begin{array}{l}-245.19-3.357 T+0.01619 T^{2}, 25^{\circ} \mathrm{C} \leq T<250^{\circ} \mathrm{C} \\ 1819.2-16.218 T+0.029 T^{2}, 250^{\circ} \mathrm{C} \leq T \leq 350^{\circ} \mathrm{C},\end{array}\right.$

The temperature-dependent isotropic hardening parameters can be fitted from strain-controlled cyclic stress at different temperatures:

$Q_{0}=\left\{\begin{array}{l}451.54-0.2573 T, \quad 25^{\circ} \mathrm{C} \leq T<200^{\circ} \mathrm{C} \\ 260+0.7 T, \quad 200^{\circ} \mathrm{C} \leq T<250^{\circ} \mathrm{C} \\ 730-1.83 T+0.0026 T^{2}, \quad 250^{\circ} \mathrm{C} \leq T \leq 350^{\circ} \mathrm{C},\end{array}\right.$

$Q_{1}=\left\{\begin{array}{l}450.778-0.15111 T, \quad 25^{\circ} \mathrm{C} \leq T<250^{\circ} \mathrm{C} \\ 268+1.03 T-0.0018 T^{2}, \quad 250^{\circ} \mathrm{C} \leq T \leq 350^{\circ} \mathrm{C},\end{array}\right.$

$Q_{\mathrm{sa}}=\left\{\begin{array}{l}404.2857+0.2857 T-0.00229 T^{2}(\mathrm{MPa}), \quad 25^{\circ} \mathrm{C} \leq T<200^{\circ} \mathrm{C} \\ 350+0.1 T(\mathrm{MPa}), \quad 200^{\circ} \mathrm{C} \leq T<250^{\circ} \mathrm{C} \\ -515+5.91 T-0.0094 T^{2}(\mathrm{MPa}), \quad 250^{\circ} \mathrm{C} \leq T \leq 350^{\circ} \mathrm{C},\end{array}\right.$

Here, units of stress and strain are $\mathrm{MPa}$ and $\mathrm{mm} / \mathrm{mm}$, respectively. It is noted that $\gamma(T)$ is set as constants of 5.0 here.

As a comparison, the material parameters for Chaboche model in finite element software ANSYS can also be obtained by fitting the experimental data, as listed in Table 2 .
Table 2 Material parameters for SA508-3 steel in the Chaboche model

\begin{tabular}{ll}
\hline Temperature $\left({ }^{\circ} \mathrm{C}\right)$ & Material parameters \\
\hline 25 & $C_{1}=7 \times 10^{3} \mathrm{MPa}, C_{2}=2.8 \times 10^{3} \mathrm{MPa}$, \\
& $C_{3}=800 \mathrm{MPa}, r_{1}=100, r_{2}=25, r_{3}=30$ \\
& $C_{1}=9 \times 10^{3} \mathrm{MPa}, C_{2}=1.5 \times 10^{3} \mathrm{MPa}$, \\
& $C_{3}=770 \mathrm{MPa}, r_{1}=100, r_{2}=25, r_{3}=30$ \\
& $C_{1}=1 \times 10^{4} \mathrm{MPa}, C_{2}=2.2 \times 10^{3} \mathrm{MPa}$, \\
& $C_{3}=474 \mathrm{MPa}, r_{1}=100, r_{2}=25, r_{3}=30$ \\
& $C_{1}=1.5 \times 10^{4} \mathrm{MPa}, C_{2}=4 \times 10^{3} \mathrm{MPa}$, \\
300 & $C_{3}=600 \mathrm{MPa}, r_{1}=250, r_{2}=25, r_{3}=30$ \\
& $C_{1}=1.6 \times 10^{4} \mathrm{MPa}, C_{2}=3.2 \times 10^{3} \mathrm{MPa}$, \\
350 & $C_{3}=820 \mathrm{MPa}, r_{1}=250, r_{2}=25, r_{3}=30$ \\
& $C_{1}=3.3 \times 10^{3} \mathrm{MPa}, C_{2}=5.8 \times 10^{3} \mathrm{MPa}$, \\
& $C_{3}=100 \mathrm{MPa}, r_{1}=250, r_{2}=25, r_{3}=30$ \\
\hline
\end{tabular}

\subsection{Simulated Results}

According to Chaboche model, the back stresses in the nonlinear kinematic rule are decomposed into several components, and each part of plastic deformation can be described by material constants $C_{i}$ and $r_{i}$ in the corresponding component, respectively. In fact, the higher accuracy can be obtained by using more components of back stress, but greater computational consumption would be cost. It is found that the material constants are relevant to the accumulated plastic strain and temperature, so the discrete material constants are modified into a continuous function. In this proposed model, not only the conservative prediction of the Chaboche model was improved, but also it is easier to determine the material constants than Chaboche model. 
Experimental and simulation results of the Chaboche model and the proposed model are compared in Figs. 1, 2 and 3. It is found that Fig. 1b, c shows the simulation results of tensile tests at different temperatures, and it is shown that both the Chaboche model and the proposed model can match the monotonic tensile curves well, since the constitutive parameters are just determined by fitting the tensile curves. From Fig. 2c, the introduced isotropic deformation rule can describe the cyclic softening and stable characteristic well, while the isotropic hardening rule is not considered in the Chaboche model. Simulated results of different temperatures are demonstrated in Fig. 3, and it is shown that the Chaboche model generally gives a large over-estimation on the ratcheting deformation. However, simulated results of the proposed model agree with the experimental ones relatively. Simulated and experimental results of ratcheting evolution under different temperatures are compared in Fig. 4b. It is shown that the proposed model can describe the ratcheting behaviors with temperature history, and some observed deformation characteristics can be reflected reasonably.

\section{Conclusions}

1. A series of monotonic uniaxial tensile tests, straincontrolled and stress-controlled cyclic experiments of SA508-3 steel have been conducted in temperature range of $25-350{ }^{\circ} \mathrm{C}$. From the experimental results, the steel shows obvious temperature-dependent ratcheting behavior. The effect of dynamic strain aging is observed between 250 and $350{ }^{\circ} \mathrm{C}$, which makes cyclic characteristic of the steel change from cyclic softening to cyclic hardening among different temperatures.

2. A temperature-dependent cyclic plastic model extended from the Chaboche kinematic hardening rule is proposed to describe the uniaxial ratcheting behavior of SA508-3 steel at elevated temperature by introducing temperature-dependent isotropic hardening and kinematic hardening rules. In the proposed model, the plastic hardening moduli $C_{i}$ was modified into a continuous function depending on the accumulated plastic strain. The proposed model provides all simulations in better agreement with the monotonic and cyclic deformation experiments at elevated temperatures than the Chaboche model.

Acknowledgements Financial supports by the National Natural Science Foundation of China (No. 11572265), the distinguished Young Scholars of Sichuan (No. 2017JQ0019) and the Science and Technology on Reactor System Design Technology Laboratory of China are appreciated.

\section{References}

[1] G. Kang, Int. J. Fatigue 30, 1448 (2008)

[2] K. Sai, Int. J. Plast 27, 250 (2011)

[3] X. Chen, X. Chen, D. Yu, B. Gao, Int. J. Pres. Ves. Pip. 101, 113 (2013)

[4] A. Mishra, P. Chellapandi, R.S. Kumar, G. Sasikala, Trans. Indian Inst. Met. 68, 161 (2015)

[5] Y.C. Lin, Z.H. Liu, X.M. Chen, J. Chen, Mater. Sci. Eng. A 573, 234 (2013)

[6] Y.C. Lin, X.M. Chen, Z.H. Liu, J. Chen, Int. J. Fatigue 48, 122 (2013)

[7] C.L. Pun, Q. Kan, P.J. Mutton, G. Kang, W. Yan, Int. J. Fatigue 66, 138 (2014)

[8] G. Kang, Q. Gao, Key Eng. Mater. 247, 275-276 (2004)

[9] C.O. Frederick, P. Armstrong, Mater. High Temp. 24, 1 (2007)

[10] J. Chaboche, D. Nouailhas, J. Eng. Mater. Tech. 111, 409 (1989)

[11] N. Ohno, J.D. Wang, Int. J. Plast 9, 375 (1993)

[12] M. Abdel-Karim, N. Ohno, Int. J. Plast 16, 225 (2000)

[13] G. Kang, Q. Kan, Mech. Mater. 39, 488 (2007)

[14] Y.C. Lin, Z.H. Liu, X.M. Chen, Z.L. Long, J. Mater. Eng. Perform. 24, 1820 (2015)

[15] D. Dong, F. Chen, Z. Cui, Mater. Sci. Eng., A 634, 103 (2015)

[16] M. Sun, L. Hao, S. Li, D. Li, Y. Li, J. Nucl. Mater. 418, 269 (2011)

[17] J. Liu, L. Wang, Y. Liu, X. Song, J. Luo, D. Yuan, Int. J. Miner. Metall. Mater. 21, 1187 (2014)

[18] M. Yaguchi, Int. J. Plast 21, 43 (2005)

[19] S. Xu, X.Q. Wu, E.H. Han, W. Ke, J. Mater. Sci. 44, 2882 (2009)

[20] J.L. Chaboche, Int. J. Plast 5, 247 (1989)

[21] J. Ahlström, E. Kabo, A. Ekberg, Wear 366-367, 378 (2016) 